Andréa Valentim Goldenzon

\title{
Ensino baseado em casos clínicos
}

Trabalho de Conclusão do Curso de Formação Docente em Medicina e Ciências da Saúde: Novas Metodologias PUC-Rio 2015.

Jorge Calmon de Almeida Biolchini

Rio de Janeiro

Outubro de 2016

Pontifícia Universidade Católica DO RIO DE JANEIRO 
À minha família, que sempre me apoiou e me incentivou a crescer profissionalmente, valorizando meu esforço e me dando suporte emocional 
Agradecimentos

Aos meus colegas, amigos carinhosos e essenciais nesse desbravamento e busca do conhecimento,

à Dra. Claudia Martins Vasconcellos Midão e Aos meus professores, guias e motivadores ao longo desta jornada; À toda a equipe de profissionais da MEDPUC, sempre solícitos, gentis e competentes, dando apoio incondicional; Em especial ao Professor Jorge Biolchini, que soube conduzir como um maestro, de maneira exemplar, as capacidades e diferenças individuais de cada aluno, valorizando cada personagem dessa longa história; À Deus, por nos guiar e fortalecer na nossa jornada em busca do conhecimento, nosso bem mais valioso. 


\section{RESUMO}

O ensino médico baseado em casos clínicos foi aplicado a alunos de Pediatria do quarto ano da Faculdade de Medicina da Fundação Técnico Educacional Souza Marques buscando avaliar a transmissão do conhecimento e a opinião quanto ao método. As competências necessárias à formação do médico abrangem aquisição de conhecimentos específicos, desenvolvimento de habilidade clínica e atitudes frente a prática profissional que possam ser avaliadas e validadas pela instituição formadora, considerando a associação de capacidades cognitivas, psicomotoras e afetivas contextualizadas no ambiente histórico e sociocultural e individualizadas pelas experiências pessoais do aprendiz. O método hipotético-dedutivo característico do raciocínio clínico exige desenvolvimento de base de conhecimento e do processo de sua aplicação. Quanto mais precoce o contato com este método, mais facilmente os alunos absorverão a linguagem e o processo. A repetição deliberada de casos é componente essencial nesta aprendizagem. Utilizamos quatro formas de preleção, casos clínicos reais no início ou final da exposição, criados pelos próprios discentes após a preleção e sem apresentação de casos. Foi aplicado questionário teórico que evidenciou, em média, que $80 \%$ responderam corretamente a 2/3 ou mais das questões. Após aplicação de todos os formatos foi realizado questionário opinativo com resposta muito favorável. A aplicação do método de Bardin reforçou o resultado e acentuou a efetividade de recursos audiovisuais e o desejo por mais dedicação às atividades práticas. O resultado dos discentes na prova realizada ao término do módulo foi comparada com o de turma anterior, mostrando apreensão de conhecimento superior $(79,5 \% / 49,6 \%$ com notas acima de $2 / 3)$.

\section{Palavras-Chave:}

Educação médica; aprendizado baseado em casos; metodologia ativa; ensino 


\section{ABSTRACT}

The medical education based on clinical cases was applied to fourth year pediatrics students of the Fundação Técnico Educacional Souza Marques medical school seeking to assess the transmission of knowledge and opinion about the method. The necessary skills for the physician formation include acquiring specific knowledge, clinical skills and attitudes toward the professional practice that can be evaluated and validated by the forming institution, whereas the association of cognitive, psychomotor and affective abilities in historical and socio-cultural environment context and individualized by the personal experiences of the apprentice. The hypothetic-deductive characteristic of clinical reasoning requires development of a knowledge base and the process of its application. The earlier the contact with this method, more easily students will absorb the language and the process. The deliberate repetition of cases is an essential component in this learning. We use four forms of lecture, actual clinical cases at the beginning or end of the exhibition, created by the students after the lecture and without presentation of cases. A theoretical survey applied showed, on average, that $80 \%$ answered correctly $2 / 3$ or more of the questions. After application of all formats an opinionated questionnaire was conducted with very favorable response. The application of Bardin method reinforced the result and highlighted the effectiveness of audiovisual resources and the desire for more dedication to practical activities. The students result in the test held at the end of the module has been compared with the previous class, showing superior knowledge apprehension $(79.5 \% / 49.6 \%$ with over $2 / 3)$.

\section{Keywords:}

medical education; case-based learning; active methodology; teaching 


\section{SUMÁRIO}

1. Introdução

Página

2. Fundamentos teóricos

3. Hipótese 17

4. Objetivo 18

4.1. Objetivo primário 18

4.2. Objetivo secundário 18

5. Materiais e métodos 19

6. Resultados 21

7. Discussão 28

8. Conclusões 31

9. Referências bibliográficas 33

10. Anexo I-casos clínicos 36

10.1 Casos clínicos de febre reumática 36

10.2 Casos clínicos de dores nos membros 37

10.3 Casos clínicos de sepsis 38 


\section{LISTAS DE ILUSTRAÇÕES}

Figura 1 - Professors Welch, Halsted, Osler And Kelly (Also Known As The Four Doctors) - John Singer Sargent - 1905-1906 - Welch Medical Library (www.the-athenaeum.org)

Tabela 1 - Pontuação da escala de Likert 20

Gráfico 1 - Questionário opinativo - Pontuação por aluno

Tabela 2 - Pontuação final por aluno

Tabela 3 - Resultado dos questionários teóricos

Gráfico 2 - Resultado do questionário sobre febre reumática

Gráfico 3 - Resultado do questionário sobre dor articular

Gráfico 4 - Resultado do questionário sobre sepse

Gráfico 5 - Resultado do questionário sobre neoplasias na infância

Gráfico 6 - Resultado do questionário sobre convulsões

Gráfico 7 - Distribuição de Notas na Prova Atual 
"O método natural de ensino começa com o paciente, continua com o paciente e termina com o paciente, usando livros e aulas como ferramentas para este fim".

William Osler (1849-1919) 


\section{1 \\ INTRODUÇÃO}

Sabe-se que no final do século XIX a descoberta dos microrganismos e a emergência da bacteriologia impuseram uma nova concepção médica onde predominava a lógica do agente etiológico. Esta nova concepção levou a uma reestruturação do ensino médico, antes influenciado predominantemente pelas escolas francesa e alemã. Grande parte desta mudança acabou sendo desencadeada em um novo centro irradiador, a América do Norte. Naquele início de século, a atuação de um grupo conhecido como o Círculo Hopkins acabou influenciando praticamente todo o ensino médico no século XX (PAGLIOSA, F. L.; DA ROS, M. A. 2008). O crédito por esta transformação tem sido atribuído principalmente a Abraham Flexner e sua crítica da educação médica contida no seu famoso 'Relatório Flexner' de 1910. Flexner, que não era médico, mas educador, foi contratado para avaliar as mais de 150 escolas médicas existentes nos Estados Unidos e no Canadá, e concluiu que a maioria deveria simplesmente ser fechada. Suas conclusões refletiam o espírito da época, que favorecia o cientificismo da medicina, mas também iam de encontro aos interesses da Associação Médica Americana, que desejava reduzir o número de médicos licenciados e a influência de escolas médicas alternativas. Um grande defensor deste movimento, William Welch, o reitor fundador da Hopkins, tinha grande influência política e era conhecido por ser um ferrenho defensor do reducionismo alemão. Via a medicina clínica como uma disciplina científica a ser ensinada por cientistas famosos. Além de defender uma sólida formação em ciências básicas, ele considerava que a medicina clínica era um ramo da fisiopatologia e que o foco de interesse era do laboratório para o leito. 


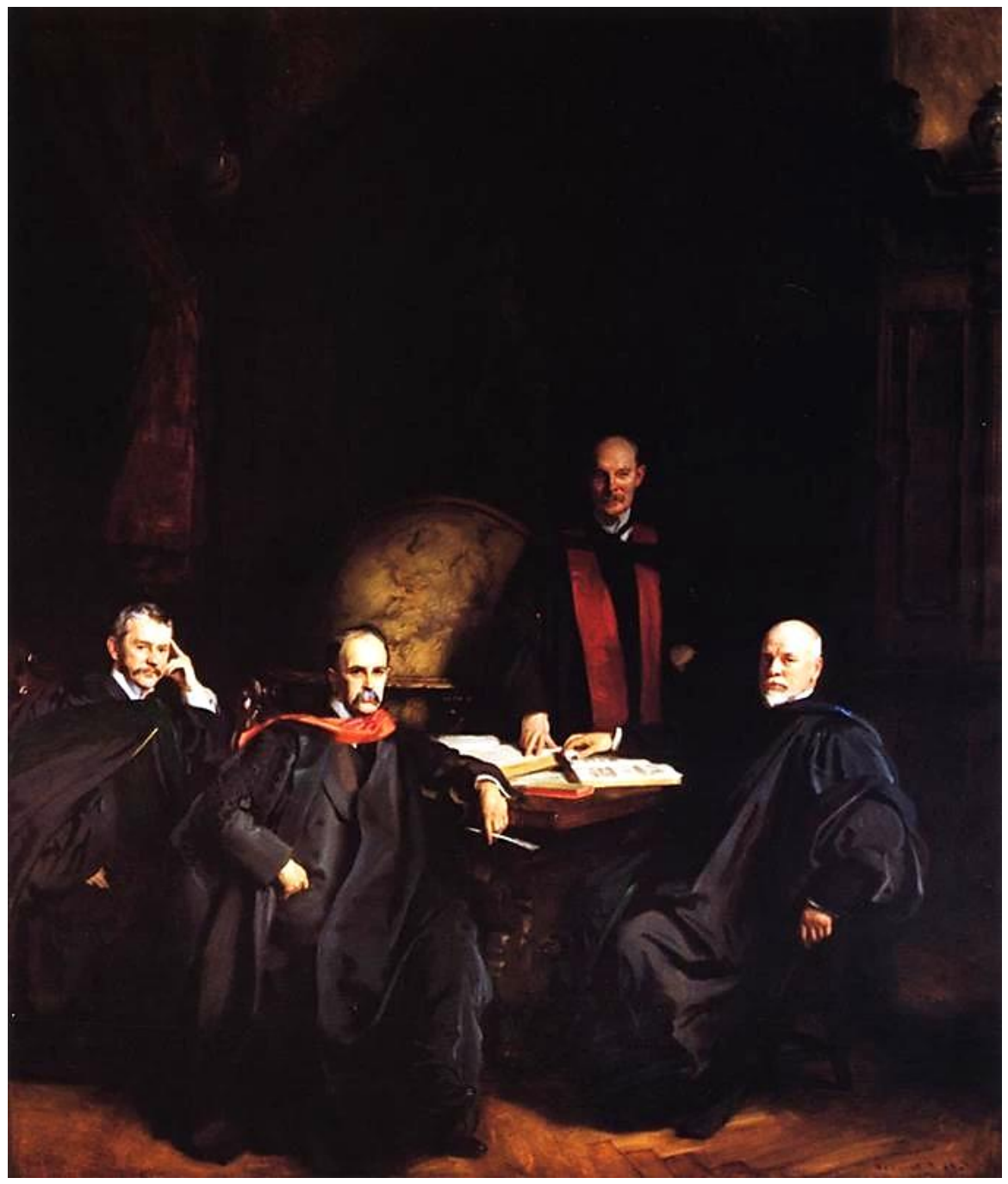

Figura 1 - The Four Doctors (1906) - The Alan Mason Chesney Medical Archives of The Johns Hopkins Medical Institutions, Baltimore. Oil on canvas. 327.7 x $271.8 \mathrm{~cm}$ (129 x 109 in.) <http://www.jssgallery.org/Paintings/The_Four_Doctors.htm\#Source>

Apesar disso, ele foi responsável pela seleção de William Osler (LOPES, A. D.; LICHTENSTEIN, A. 2007) para o cargo de primeiro chefe de medicina da Hopkins. Osler tinha uma visão oposta a Welch quanto ao ensino médico e acreditava que o vetor crucial deveria ser da cabeceira do leito para o laboratório, tendo rejeitado o relatório de Flexner, alertando contra a nomeação de professores com base em realizações de pesquisas em oposição de interesses de alunos e pacientes, tanto por causa do perigo de desviar os alunos para o laboratório como pela suposta insuficiência destes cientistas como professores clínicos. Apesar do grande respeito que o Dr. Osler gozava entre seus pares, Welch e Flexner acabaram por consolidar suas teorias, que modificaram a formação do médico ao redor do mundo (TAUBER, A. I. 1992) 
Esta disseminação foi facilitada por um terceiro membro do grupo, Frederick Gates, conselheiro de confiança de Rockefeller. Gates convenceu Rockefeller a fornecer seus recursos filantrópicos para alcançar os objetivos do grupo. A fundação Rockefeller teve forte influência na propagação das metodologias contidas no relatório Flexner (COOKE, M.; et al. 2006)

A nova metodologia gerou uma elitização da formação médica, com o consequente aumento de custo para os pacientes e uma tendência crescente de especialização e dependência tecnológica. É importante ressaltar que apesar de forte defensor do cientificismo baseado na escola alemã, Flexner considerava as atividades práticas, tanto no laboratório como na clínica, essenciais ao aprendizado médico, combatendo o ensino por meio de conferências e aprendizado pela simples memorização, o que permite considerá-lo um precursor das metodologias ativas de ensino.

A forma atual da regulamentação da medicina no Brasil, e consequentemente de sua formação, implantada a partir da década de 1930, foi fortemente influenciada pela atuação Fundação Rockefeller. Foi esta fundação que trouxe para o Brasil a chamada Reforma Flexner, que preconizava que os professores de medicina, fossem de ciências básicas ou de ensino clínico, deveriam ser especializados e dedicar-se exclusivamente ao ensino e à pesquisa.

As concepções destes professores médicos quanto ao método de ensino e sua própria concepção sobre a medicina e a ciência tiveram papel importantíssimo na definição dos currículos e no desenvolvimento das instituições de ensino universitário. A universidade seguiu a tendência da época, dedicando-se à pesquisa e à produção científica.

Desde então praticamente inalterado, o currículo das faculdades de medicina gradualmente vem sendo reformulado. A preocupação com a integridade do paciente em face a expansão tecnológica, crescente especialização, a reestruturação das organizações de serviço de saúde e a uma degradação da educação geral dos médicos levou a uma nova ênfase no treinamento clínico mais precoce e numa expansão da abordagem sociológica, incluindo a preocupação humanística, ética, relacional e socioeconômica na relação médico-paciente (BULCÃO, L. G.; ELKAREH, A. C.; SAYD, J. D. 2007). 
As competências necessárias à formação do médico abrangem a aquisição de conhecimentos específicos, o desenvolvimento de habilidade clínica e de atitudes frente aos vários aspectos da prática profissional que possam ser avaliadas e validadas pela instituição formadora. Esta concepção ampliada de competência passa a considerar a associação de capacidades cognitivas, psicomotoras e afetivas contextualizadas no ambiente histórico e sociocultural e individualizadas pelas experiências pessoais do aprendiz (LIMA, V. V. 2005). O raciocínio clínico, a habilidade mais crítica do médico e o ingrediente mais importante para a construção de sua competência é buscado pelo método hipotético-dedutivo, que exige o desenvolvimento tanto de uma extensa base de conhecimento quanto do processo de sua aplicação na busca de uma solução para o problema do paciente (RÉANETO, A. 1998).

Em 1984 a Associação Americana de Faculdades de Medicina publicou um relatório sobre a situação da educação médica nos Estados Unidos (GPEP) (Association of American Medical Colleges 1984) que concluiu que a educação superior profissional, começando na faculdade e continuando durante os anos iniciais da residência, deveria desenvolver habilidades analíticas e diagnósticas eficazes, bem como incutir valores que promovessem o respeito e a preocupação com os pacientes, enfatizando o papel da promoção da saúde e prevenção de doenças nos currículos de educação médica. Afirmava a necessidade de incentivar que as novas admissões buscassem candidatos com uma educação de base ampla. Considerava que a busca pelo maior desenvolvimento do pensamento crítico era mais importante que o domínio das técnicas atuais e que a aprendizagem independente deveria ser estimulada (MATOS, J. 2008).

No Brasil, seguindo caminhos semelhantes, houve recentemente uma avaliação das escolas médicas pela Comissão Interinstitucional Nacional de Avaliação do Ensino Médico (Cinaem) que formulou diagnósticos preocupantes. O Ministério da Educação e Cultura (MEC), por meio de outras avaliações também encontrou diversos problemas, como baixa qualidade e qualificação dos professores, baixa produção de conhecimento, dissociação entre teoria e prática e entre ciclo básico e clínico, desumanização e descontextualização da prática, incorporação indiscriminada de tecnologias e currículos arcaicos (BRASIL. 2014) 
Esta situação acabou por estimular o lançamento das Diretrizes Curriculares Nacionais (DCN) do Curso de Graduação em Medicina, buscando definir os princípios, fundamentos, condições e procedimentos da formação médica. Esse modelo apresenta como objetivo alcançar um perfil do médico egresso como um profissional com formação generalista, humanista, crítica e reflexiva, capacitado a atuar, pautado em princípios éticos, no processo de saúde-doença em seus diferentes níveis de atenção, com ações de promoção, prevenção, recuperação e reabilitação à saúde, na perspectiva da assistência, com senso de responsabilidade social e compromisso com a cidadania, como promotor da saúde integral do ser humano. Pelas DCN, o eixo do desenvolvimento curricular deve ser o das necessidades de saúde da população, promovendo a interação entre ensino, serviço e comunidade. As Diretrizes também propõem novas estratégias de ensino-aprendizagem e de avaliação do aprendizado (BRASIL. 2001; ALMEIDA. M. J. et al. 2007)

Mesmo com esta necessidade de mudanças enfatizada nas últimas décadas e recomendada pelas DCN, o modelo tradicional de ensino ainda impera. Nele, o processo de ensino-aprendizagem é centrado no professor, que deve transmitir ao aluno o conteúdo curricular, de forma objetiva e sistemática, uma visão do conhecimento de modo fragmentado, induzindo o docente e o discente a atuarem numa perspectiva metodológica de ensino fundamentada na dicotomia teoria e prática. Segundo Ramos (RAMOS, P. 2010), é preciso que haja mudança tanto no campo da educação quanto na saúde e que o profissional assuma uma atitude de constante aprendizagem ao longo da vida ampliando sua capacidade de análise e ação. O aluno deve ser instigado a refletir e produzir conhecimento a partir de situações que acontecem na prática (BRASIL. 1996). Para tal, o egresso deve ter alcançado algumas competências essenciais para o exercício da profissão. Ele deverá ser um profissional ético, que tenha conhecimento técnico, mantendo-se atualizado, que saiba trabalhar em equipe, inclusive como gestor, e com capacidade de se comunicar de forma clara tanto com seus pacientes quanto com outros profissionais (POMBO O. 1994).

O uso generalizado da informática permitiu o desenvolvimento de inúmeros recursos de ensino, tanto presencial quanto à distância, e modificou inclusive o tipo de informação a ser memorizada e a capacidade de atualização. Entretanto, o entendimento de como estes recursos devem ser incorporados ao processo de formação do médico ainda está em discussão, tanto para determinar sua efetividade 
quanto para compará-los com o ensino tradicional. Muitos destes recursos são altamente complexos e exigem investimentos que podem limitar sua generalização. A decisão de qual ferramenta tecnológica melhor se adapta a um objetivo pedagógico requer inicialmente uma discussão de qual é o objetivo do aprendizado. Esta necessidade educacional é que deve determinar a tecnologia e não o contrário. Do mesmo modo que ocorreu há um século com a padronização curricular imposta pelo Relatório Flexner, podemos estar passando por uma nova revolução no ensino médico. Como naquela ocasião, houve uma clara melhora na formação profissional, mas uma concomitante limitação ao número de novos aprendizes e consequentemente um aumento do custo da medicina para a população (AAMC 2007).

O largo espectro de tecnologias aplicadas ao ensino médico varia das mais simples, como aquelas que permitem a busca e navegação por textos e imagens ou de recursos para a sala de aula, como BlackBoard, questionários informatizados ou ensino à distância, até recursos iterativos de alta complexidade como manequins robóticos e simuladores cirúrgicos. O desafio atual de todos aqueles envolvidos na formação de novos profissionais é determinar a melhor utilização destes recursos na formação de profissionais com as características discutidas acima (AAMC 2007). 


\section{FUNDAMENTOS TEÓRICOS}

A metodologia ativa está fundamentada nas recomendações descritas nas Diretrizes Curriculares Nacionais que preconizam que a formação do médico necessita de uma visão ética, humanista, colaboradora, pautada em conhecimento teórico abrangente, conduzindo a um adequado processo de tomada de decisão. Este processo de tomada de decisão exige que o médico tenha a habilidade de elaborar a própria experiência através do pensamento crítico, ou seja, a competência clínica não é só adquirida pelo aprimoramento da educação médica e da prática profissional, mas também pela capacidade, de forma similar ao método socrático, de análise crítica da informação.

Sócrates observou que seus alunos geralmente perdiam suas habilidades de justificar os próprios pensamentos pré-concebidos e crenças depois de uma série de perguntas específicas e direcionadas. Através de perguntas apropriadas e repetitivas observou que esses mesmos alunos eventualmente desenvolviam conhecimento auto-gerado e habilidade de regular os seus próprios pensamentos. A arte do questionamento socrático descreve os três tipos de perguntas que, quando usadas estrategicamente pelo questionador podem levar os alunos a regular seus próprios pensamentos. Essas perguntas são categorizadas como procedurais, preferenciais e de julgamento. As procedurais são definidas como aquelas com resposta certa. Perguntas de preferência são aquelas sem resposta correta. Finalmente, é no terceiro tipo de pergunta onde a definição socrática de pensamento crítico pode ser encontrada. O pensamento crítico em meio ao paradigma socrático pode ser descrito como a aplicação e análise de informação demandando claridade, consistência lógica e auto-regulação (OYLER, D. R.; ROMANELLI, F. 2014)

Exceto pelo processo de aprendizagem inato, como no ato de aprender a andar e falar, a maioria das novas informações é adquirida pela aprendizagem sintética, na qual os seres humanos adquirem novos conhecimentos, desenvolvem competências e mudam comportamento por estímulos externos e internos. A aprendizagem se faz por vários meios, entre eles as diferentes técnicas de ensino, no qual o professor é o mediador na construção da aprendizagem. É nesta mediação que caberá o estímulo ao pensamento crítico. 
O professor tem a grande vantagem inicial de contar com uma crença do aprendiz em sua capacidade de transmitir conhecimento, o que lhe permite estimular o aluno a tomar para si, de uma forma progressiva, a função de construir seu conhecimento e a percepção do modo como o faz, ou seja, seu metaconhecimento. O objetivo final deverá ser capacitar o aprendiz a controlar seu próprio processo cognitivo, aprendendo a aprender. Essa capacitação metacognitiva é essencial também para a execução de tarefas, pois envolve áreas tão díspares como a comunicação e a resolução de problemas. (RIBEIRO, C. 2003)

No ensino baseado em casos clínicos várias metodologias ativas, como mapeamento conceitual e PBL (AMOAKO-SAKYI, D.; AMONOO-KUOFI, H. 2015; BLIGH, J. 1995), podem ser aliadas na descrição ou simulação de situações reais que trazem a experiência da beira do leito para dentro da sala de aula, combinando o componente intuitivo do processo cognitivo com os conceitos científicos e técnicos característicos do componente analítico (ALMEIDA, A. P. S.; SOUZA, N. V. D. O. 2005). O estudo de casos é como um precursor dos planos de cuidados, tidos como o primeiro passo a se alcançar o que hoje é definido como foco de individualização do cuidado a pessoa, família e comunidade, com vistas à integralidade do ser e autonomia profissional. O ensino baseado em casos clínicos estimula o aprendiz a articular os componentes intuitivos e analíticos, a teoria e a prática, na busca de soluções para problemas reais buscando capacitá-lo para tomar decisões em condições incertas e subjetivas. (DA SILVA, R. S 2014) 


\section{3 \\ HIPÓTESE}

O uso de caso clínico no processo de ensino facilita a aquisição do conhecimento pois trata-se de um método ativo que estimula o aluno a buscar por informações e sua transformação em conhecimento, além de exercitar o raciocínio clínico, um dos objetivos finais da formação médica (BRIAN, M.; PAT, D. 2004). 


\section{4}

OBJETIVO

O presente trabalho busca avaliar a efetividade pedagógica de preleções dialogadas com temas pediátricos para alunos do quarto ano de medicina da Faculdade de Medicina da Fundação Técnico Educacional Souza Marques, vinculadas ou não a presença de casos clínicos criados pelos discentes ou pelos docentes, antes ou depois das preleções.

A proposta apresentada está fundamentada nas recomendações descritas nas Diretrizes Curriculares Nacionais para a formação de um novo perfil de profissional.

\section{1}

\section{Objetivo primário}

Avaliar a aprendizagem dos alunos com a metodologia ativa baseada em casos clínicos.

\section{2 \\ Objetivos secundários}

Comparar três formatos distintos de utilização de casos clínicos;

Avaliar a opinião dos alunos sobre a metodologia e

Avaliar o aprendizado através de questões objetivas e da prova teórica objetiva. 


\section{5 \\ MATERIAIS E MÉTODOS}

Estudo prospectivo, observacional usando metodologia quantitativa e qualitativa (estudo misto) Análise de dados quantitativa em planilha com média, mediana e moda e qualitativa por categorização segundo Bardin.

Foram utilizados quatro formatos distintos de apresentação:

1. Preleção dialogada sem utilização de casos clínicos

2. Apresentação de casos clínicos antes de preleção dialogada

3. Apresentação de casos clínicos após preleção dialogada

4. Criação de casos clínicos pelos alunos após preleção dialogada

Os casos (Anexo I) foram estruturados a partir de conceitos crescentes de complexidade, objetivando alcance das dimensões desejadas, gerando um domínio de conhecimento no qual essas habilidades poderiam ser despertadas.

Após assinatura de termo de consentimento informado livre e esclarecido autorizado a partir da Plataforma Brasil (CAAE 56674916.3.0000/5239), foi realizada a aplicação dos casos em sala de aula, seguida da realização das avaliações após preleção dialogada. $\mathrm{O}$ estudo foi realizado durante o período que os alunos permaneceram na disciplina de pediatria do quarto ano da faculdade de medicina da Fundação Técnico Educacional Souza Marques.

Todas as aulas foram seguidas de avaliação teórica através de três questões de múltipla escolha sobre o tema abordado visando mensurar a absorção dos conceitos expostos. Esta avaliação teve como objetivo mapear o processo de ensino-aprendizagem do discente.

Posteriormente foi realizada a comparação entre os resultados destes alunos em prova objetiva com os resultados da turma anterior, não submetida a mesma metodologia de ensino.

Após o término do módulo de pediatria, foi aplicada uma pesquisa de opinião com questões utilizando escala de Likert de cinco pontos visando avaliar a visão dos discentes sobre a metodologia utilizada. As perguntas do questionário apresentavam as opções de resposta identificadas com letras de "a" até "e". Cada uma tinha um valor numérico associado usado para a quantificação dos resultados. 


\begin{tabular}{|l|c|}
\hline Opção & Valor \\
\hline Concordo fortemente & 5 \\
\hline Concordo & 4 \\
\hline Indiferente & 3 \\
\hline Discordo & 2 \\
\hline Discordo fortemente & 1 \\
\hline
\end{tabular}

Tabela 1 - Pontuação da escala de Likert

Considerando estes valores, a maior pontuação que poderia ser obtida no questionário era 35. As respostas coletadas foram tabuladas no software Microsoft Excel 2010 e a partir delas foram obtidas as notas gerais, médias, medianas e geradas tabelas e gráficos para apresentar os resultados encontrados. 


\section{6 \\ RESULTADOS}

Os resultados foram obtidos após a avaliação dos questionários de 35 alunos do curso de graduação. A avaliação dos resultados ocorreu através da análise quantitativa iniciada pelas respostas ao questionário de avaliação seguida pela verificação do aprendizado baseada no percentual de acertos nos questionários aplicados após a preleção e, por último, do desempenho na prova. Posteriormente foi realizada a análise qualitativa segundo categorização de Bardin.

Dos 35 alunos que foram submetidos ao questionário, 20 concordaram fortemente e 15 concordaram que "O formato de caso clínico é apropriado para o aprendizado deste assunto" (primeira questão), coincidindo com os 17 que concordaram fortemente e os 16 que concordaram que "A atividade de apresentação de casos clínicos promove um envolvimento maior com o assunto" (segunda questão). Apenas 2 consideraram-se indiferentes. Mais controversa, a terceira questão, que perguntava se a "A criação de casos clínicos pelos alunos após a preleção dialogada é benéfica para aprendizagem" foi a que teve o menor número de alunos que concordaram fortemente (COOKE, M.; et al. 2006), enquanto 14 concordaram e 8 foram indiferentes. Esta questão apresentou a única discordância em todo o questionário. As respostas se "a apresentação de casos clínicos reais, contendo a anamnese e exame físico e exames complementares é benéfica para aprendizagem" (quarta questão), se "as atividades foram objetivas" (sexta questão) e se o aluno "recomendaria essas atividades para os grupos seguintes" (sétima questão) tiveram respostas muito semelhantes com respectivamente 23, 24 e 23 concordando fortemente e o restante (BULCÃO, L. G.; EL-KAREH, A. C.; SAYD, J. D. 2007) apenas concordando. A maior concordância ocorreu na quinta questão, quando 31 concordaram fortemente e quatro concordaram que "a apresentação de casos clínicos criados pelo professor, após a preleção dialogada, ressaltando os pontos importantes da aula ajudam no aprendizado" 
O resultado da somatória de pontos de cada aluno pode ser verificado abaixo (gráfico 1).

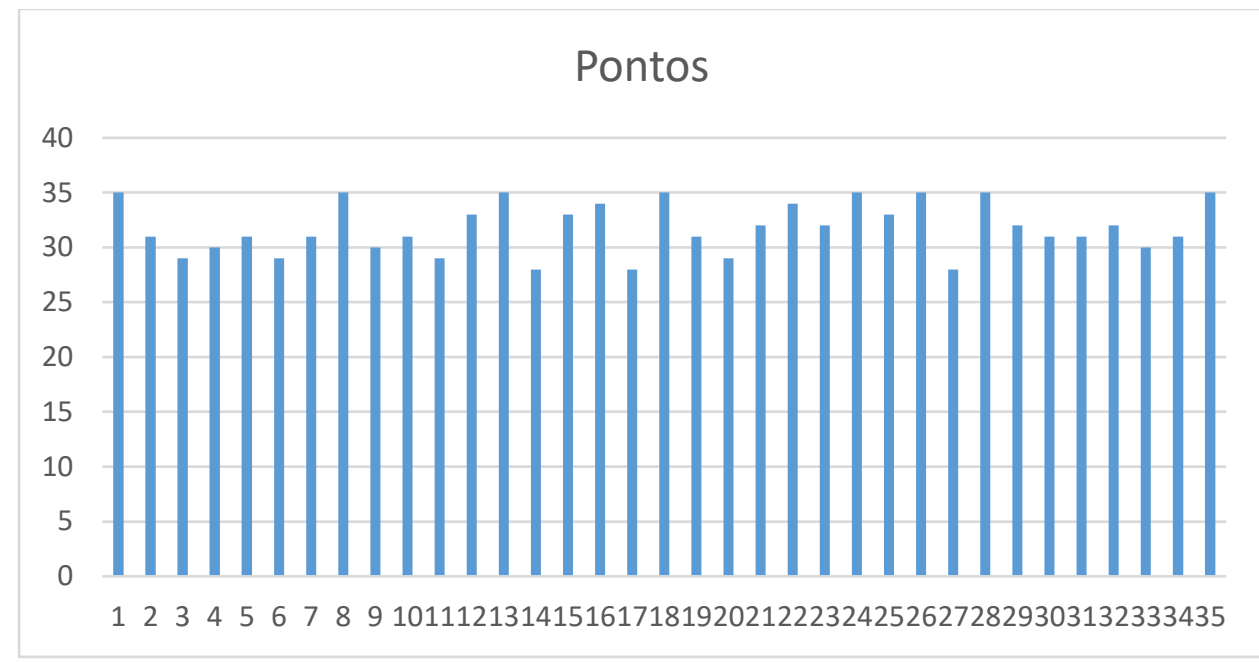

Gráfico 1 - Questionário opinativo - Pontuação por aluno

A análise quantitativa da pontuação final de cada participante (tabela 2) evidenciou uma média muito próxima a nota máxima possível (TANCREDI, F. B.; FEUERWERKER, L. C. M. 2001) com uma mediana de 31 e uma moda de 35, sugerindo uma forte concordância com todas as afirmativas, e, portanto, uma grande aceitação do formato pelos discentes.

\begin{tabular}{|ll|c|c|c|c|c|c|c|c|c|c|c|}
\hline Pontos & 28 & 29 & 30 & 31 & 32 & 33 & 31 & 35 & 31,8 & 31 & 31 \\
\hline $\begin{array}{l}\text { Número } \\
\text { alunos }\end{array}$ & 3 & 4 & 3 & 8 & 4 & 3 & 2 & 8 & Média & Mediana & Moda \\
\hline
\end{tabular}

Tabela 2 - Pontuação final por aluno

A análise qualitativa pela técnica proposta por Bardin foi estruturada de forma a promover uma avaliação dos dados em fases ou etapas que conduzam a um resultado estruturalmente organizado do conteúdo. A análise seguiu as fases de préanálise com leitura flutuante dos dados coletados, através do qual o conteúdo foi se tornando mais claro em função dos pressupostos emergentes nas falas dos entrevistados e do objetivo que fundamenta a interpretação final. Em seguida foram organizadas as falas segundo as respostas de cada entrevistado que optou por redigir, não sendo obrigatório. Nessa fase se deu a exploração das falas, transformando-as em unidades temáticas, resultando estas em categorias de análise. 
Na última etapa, de inferência, aconteceu o tratamento dos resultados a partir da interpretação das falas, identificando-se as expressões-chave de cada resposta, buscando pontos semelhantes e divergentes, procurando-lhes os sentidos duplos, intenções, comparações, avaliações e identificações de pensamentos que representassem a compreensão dos graduandos acerca do estudo de caso.

Em relação aos comentários/ sugestões por extenso, apenas nove participantes escreveram. Quatro alunos acharam que a introdução de imagens foi um facilitador do aprendizado, sendo que um deles ressaltou que o uso de casos estimula o aprendizado. Dois alunos utilizaram a palavra "excelente" para introdução de casos clínicos no aprendizado, porém um dos alunos gostaria de ter mais tempo nas aulas práticas, para aplicar o conhecimento adquirido. Um aluno sugeriu casos que sejam mais extensos, com evolução e prognóstico, acompanhados de todos os exames relevantes. Um aluno acredita que quando eles próprios montam o caso o aprendizado é mais sólido, mas esta impressão parece ser a mais controversa entre os alunos, vide o resultado da terceira questão. Um aluno considerou que a utilização dos casos clínicos foi "extremamente válida" para memorização do assunto. Outro sugeriu um número ainda maior de casos, apesar de termos utilizado quatro casos por assunto.

Dos resultados emergiram algumas categorias para análise: o uso de imagens no estudo de casos facilita o aprendizado, que seria desejável maior tempo dedicado às atividades práticas para permitir a correlação do ensino baseado em casos com o atendimento ao paciente e que quanto mais complexo e detalhado o caso, maior é a motivação do aluno.

As avaliações realizadas imediatamente após as preleções dialogadas constavam de três questões de múltipla escolha. Consideramos o acerto de 0 ou 1 questão como demonstração de ineficácia do aprendizado e o acerto de 2 ou 3 questões como resultado satisfatório. Os resultados evidenciados na tabela 3 demonstram um resultado satisfatório em média de $80 \%$ dos alunos testados. 


\begin{tabular}{|l|c|c|c|c|c|c|}
\hline Questões & 0 & 1 & 2 & 3 & Soma 0 e 1 & Soma 2 e 3 \\
\hline FR & 0 & 10 & 10 & 16 & 10 & 26 \\
\hline & $0 \%$ & $28 \%$ & $28 \%$ & $44 \%$ & $28 \%$ & $72 \%$ \\
\hline Dor articular & 4 & 9 & 19 & 0 & 13 & 19 \\
\hline & $13 \%$ & $28 \%$ & $59 \%$ & $0 \%$ & $41 \%$ & $59 \%$ \\
\hline Sepse & 0 & 4 & 8 & 22 & 4 & 30 \\
\hline & $0 \%$ & $12 \%$ & $24 \%$ & $65 \%$ & $12 \%$ & $88 \%$ \\
\hline Neoplasia & 0 & 3 & 19 & 12 & 3 & 31 \\
\hline & $0 \%$ & $9 \%$ & $56 \%$ & $35 \%$ & $9 \%$ & $91 \%$ \\
\hline Convulsões & 0 & 2 & 6 & 7 & 2 & 13 \\
\hline & $0 \%$ & $13 \%$ & $40 \%$ & $47 \%$ & $13 \%$ & $87 \%$ \\
\hline Prova & 0 & 9 & 16 & 19 & 9 & 35 \\
\hline & $0 \%$ & $20 \%$ & $36 \%$ & $43 \%$ & $20 \%$ & $80 \%$ \\
\hline
\end{tabular}

Tabela 3 - Resultado dos questionários

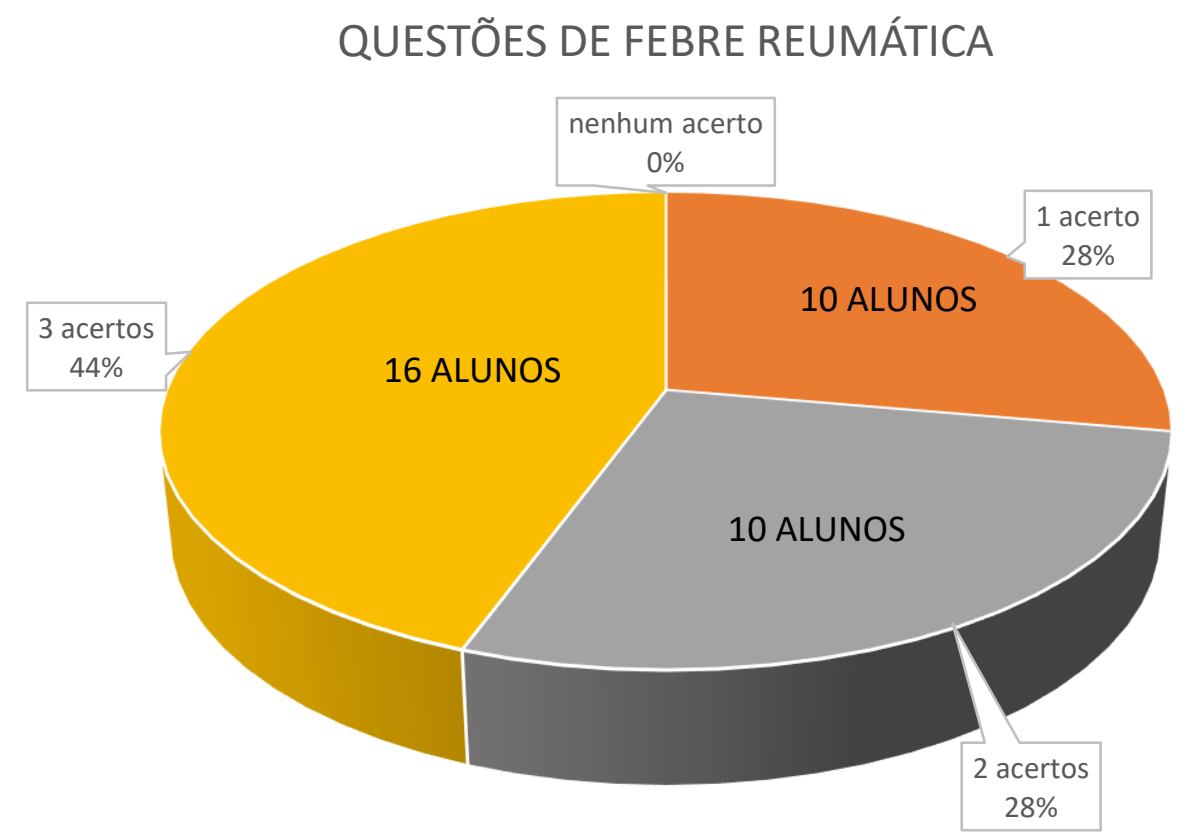

Gráfico 2 - Resultado do questionário sobre febre reumática 


\section{QUESTÕES DE DOR ARTICULAR}

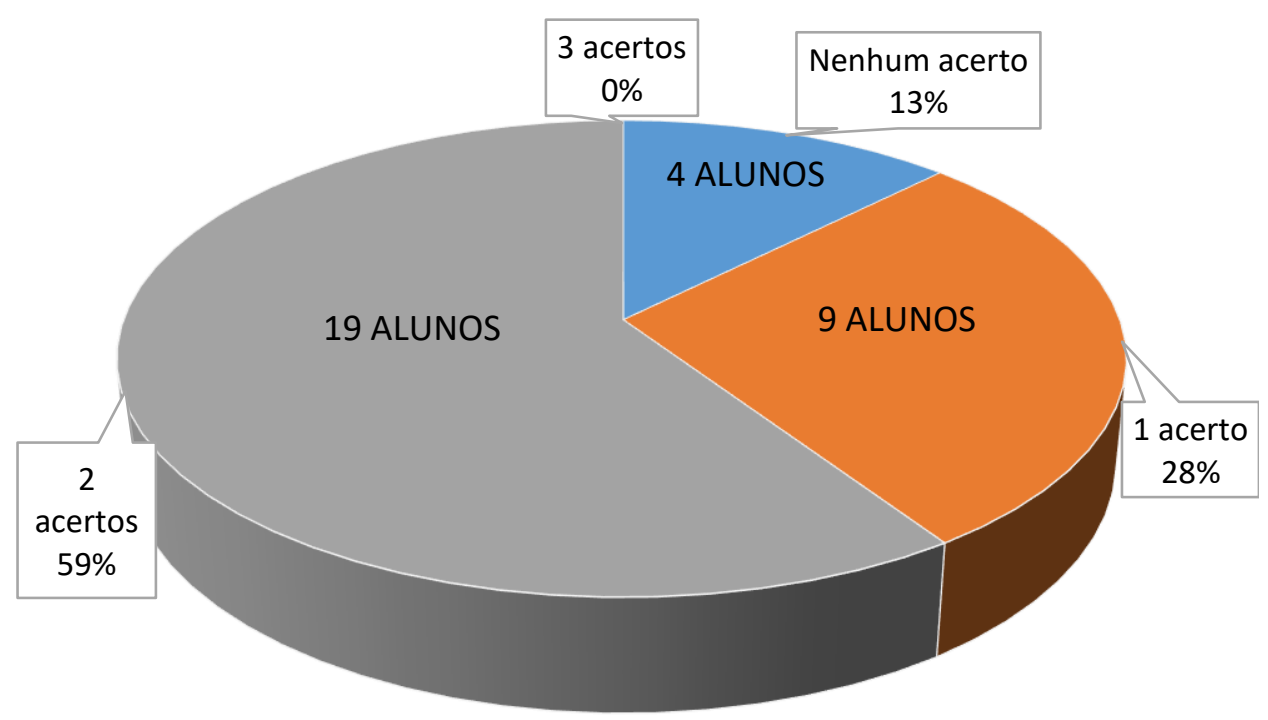

Gráfico 3 - Resultado do questionário sobre dor articular

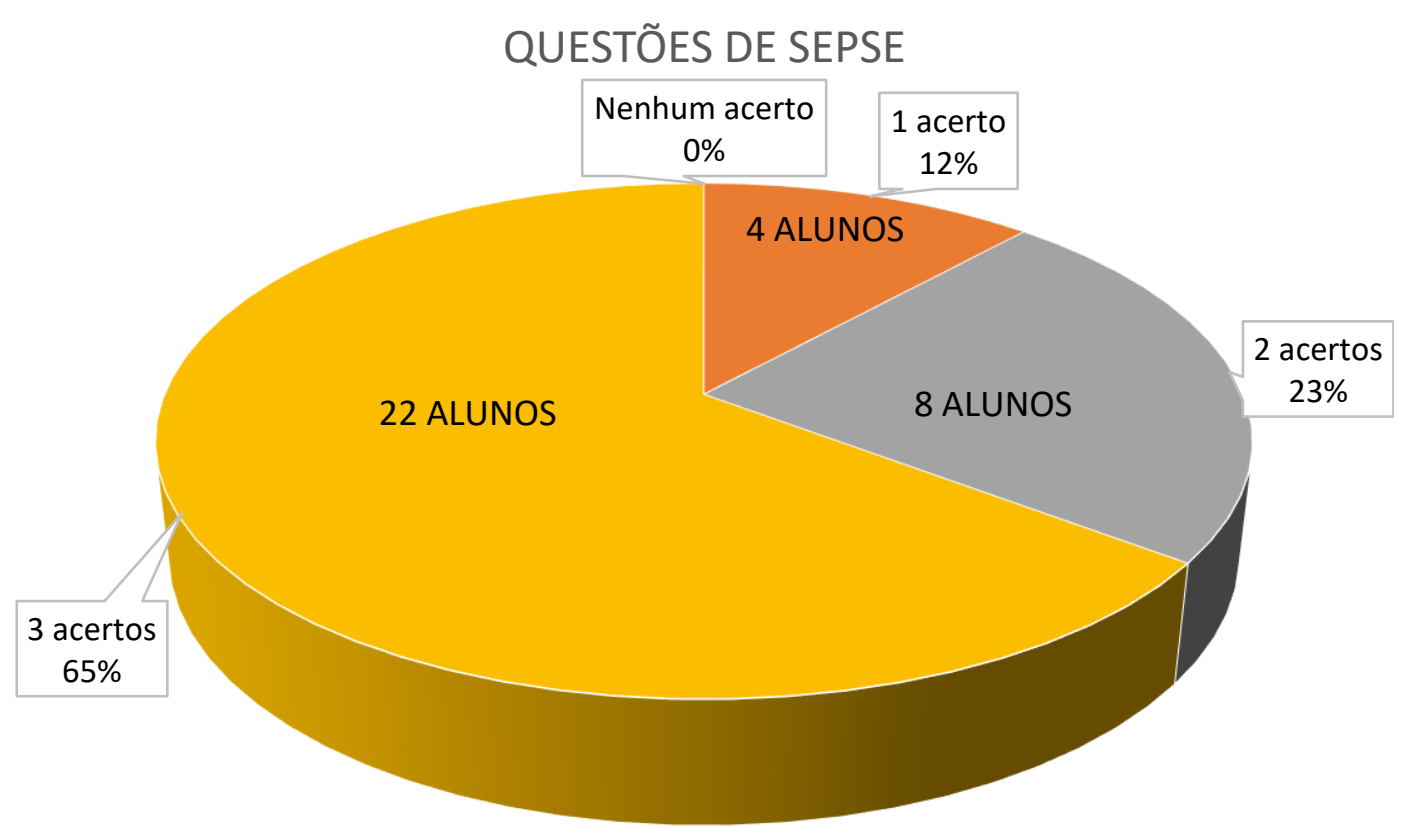

Gráfico 4 - Resultado do questionário sobre sepse 


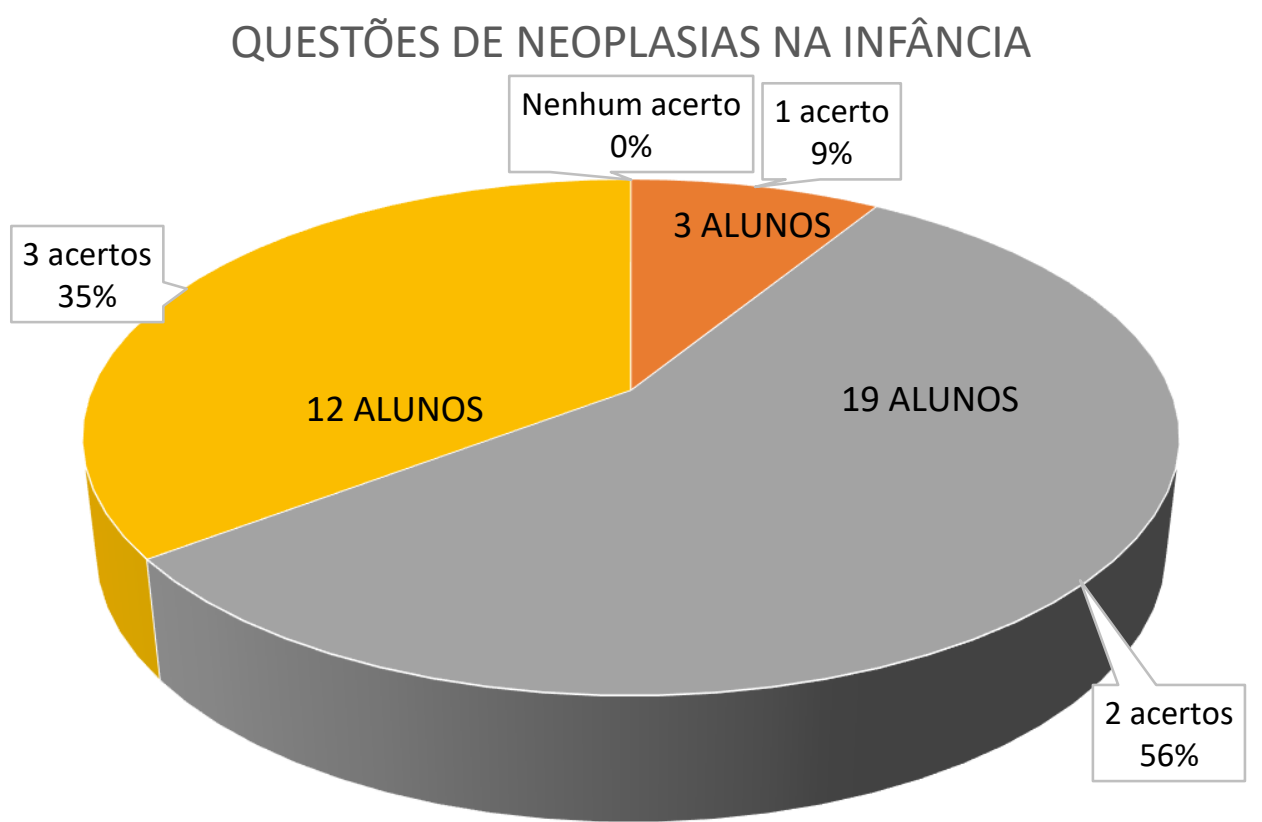

Gráfico 5 - Resultado do questionário sobre neoplasias na infância

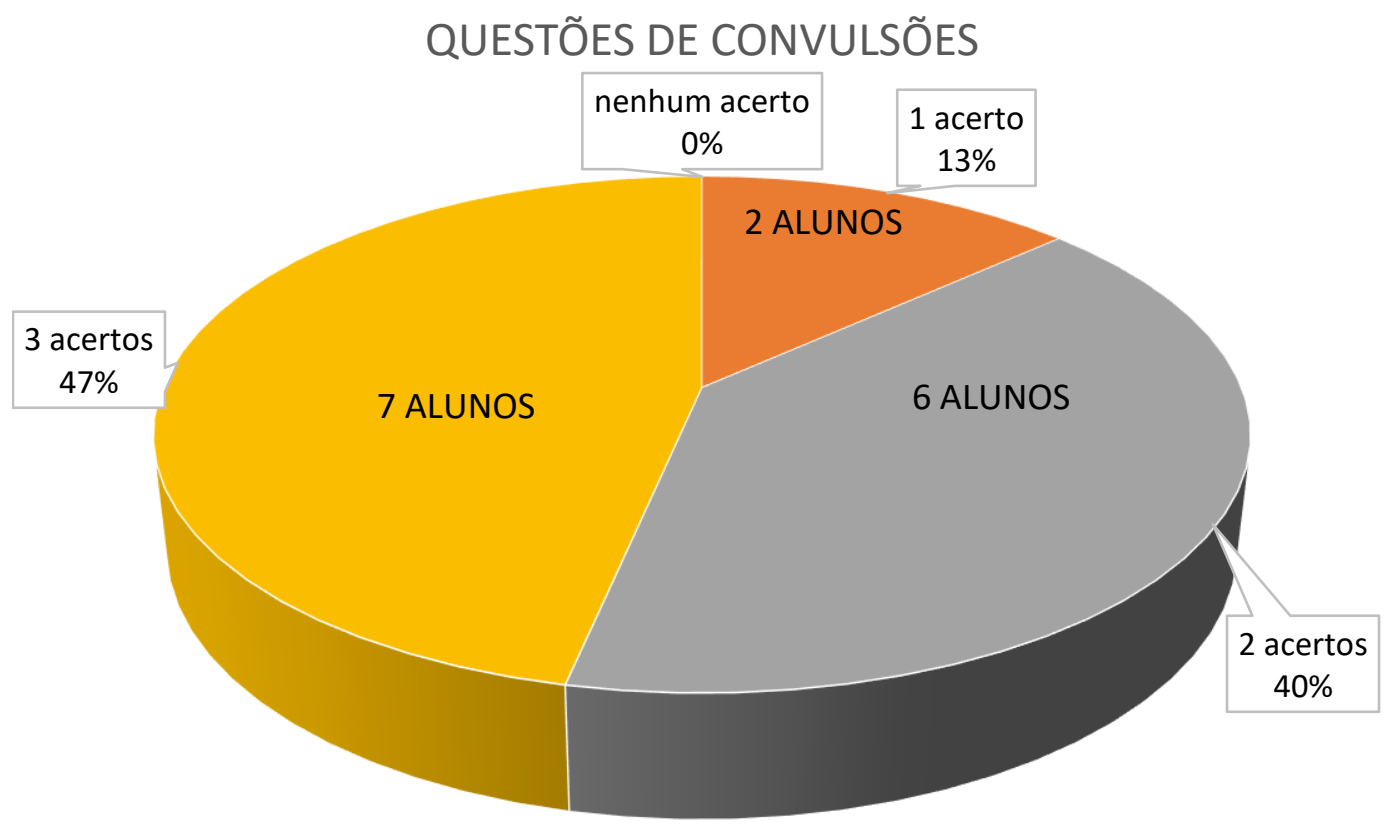

Gráfico 6 - Resultado do questionário sobre convulsões 
Esta média foi compatível com a média de acertos na prova teórica, quando $79,5 \%$ dos alunos acertaram $2(36,3 \%)$ ou $3(43,2 \%)$ das 3 questões de reumatologia pediátrica (gráfico 3), um resultado muito superior ao alcançado pela turma anterior, que recebera as preleções dialogadas sem a associação ao método proposto. Na avaliação anterior somente $49,6 \%$ dos alunos tiveram resultados satisfatórios (igual ou maior que 2/3), como pode ser visto no gráfico 4 .

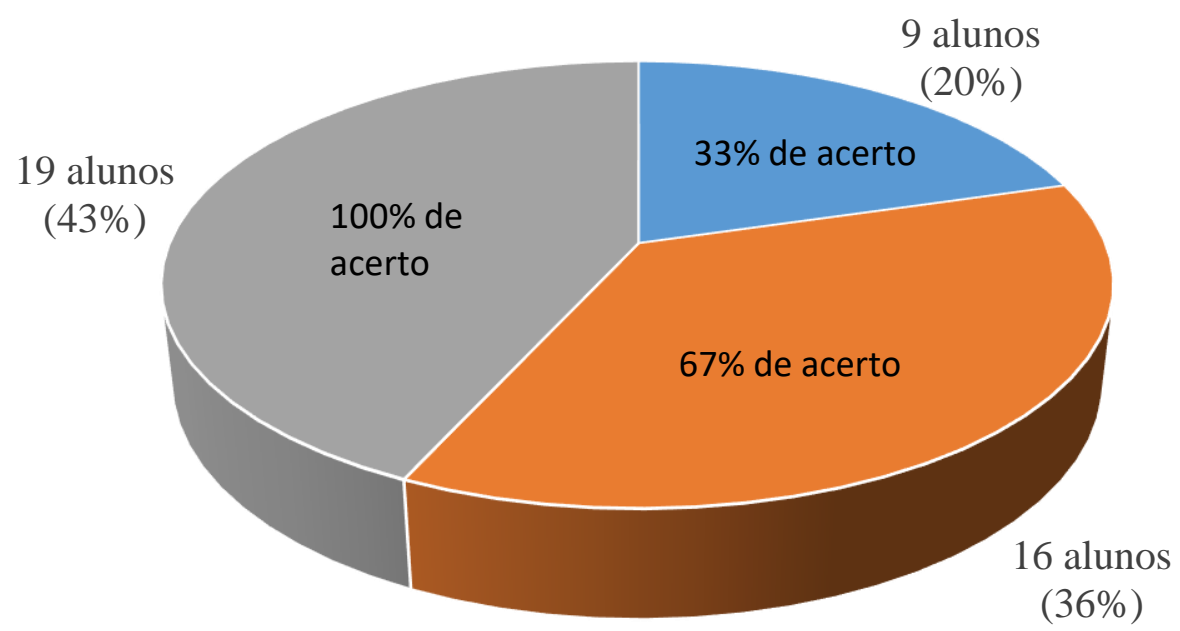

Gráfico 7 - Distribuição de Notas na Prova Atual

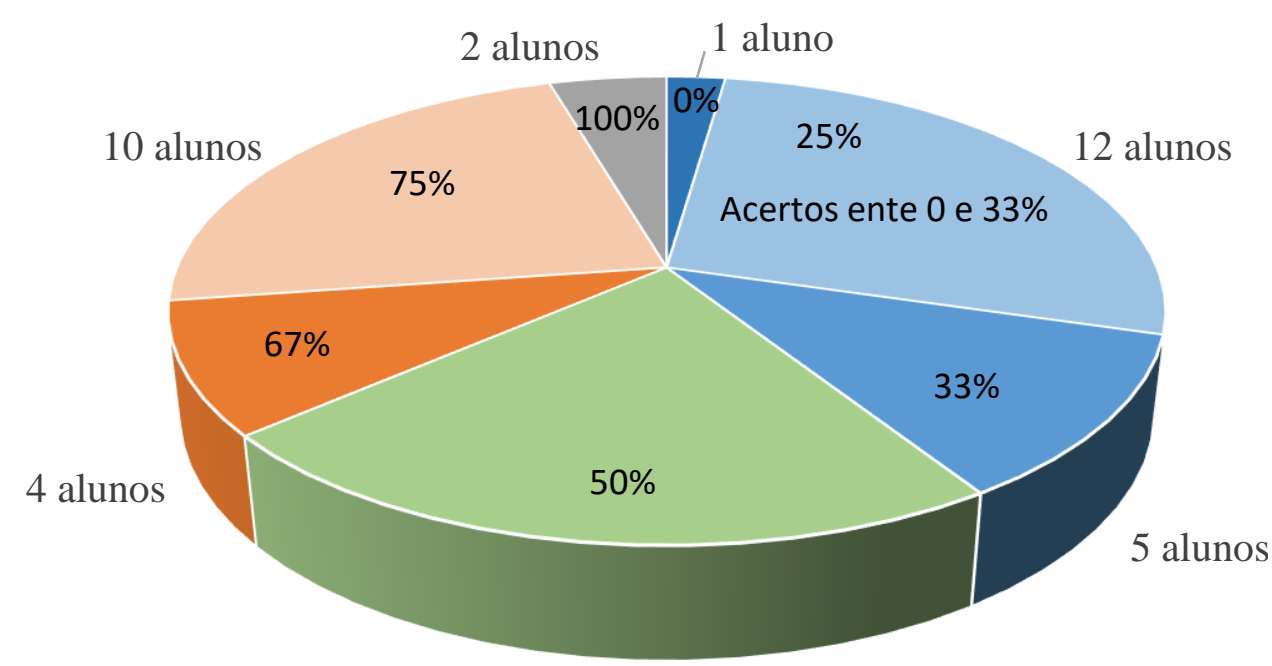

10 alunos

Gráfico 8 - Distribuição de Notas na Prova Anterior 


\section{7 \\ DISCUSSÃO}

O aprimoramento da prática médica começa pelo reconhecimento da dúvida sobre qual procedimento diagnóstico ou terapêutico é mais eficaz para um determinado paciente. Que estratégia diagnóstica seria mais adequada? Qual a conduta terapêutica mais indicada considerando as variáveis existentes? Quais as medidas efetivas para minimizar as complicações? Existem muitos outros questionamentos na rotina do médico que exigem um processo de aprendizagem que permita sua participação ativa e autônoma na construção do conhecimento. Neste contexto, o estudo contribui para demonstrar que a utilização de discussões construídas em formato de caso clínico contribui para melhorar o processo de construção do método de análise crítica, estimulando a inter-relação do indivíduo com suas habilidades e conhecimentos objetivos e aumentando a habilidade do médico em tomar decisões diante de situações clínicas reais (AMORETTI, R. 2005)

Hernandez (HERNANDEZ, C. C.; et al. 2012) apresentou avaliação do ensino baseado em casos clínicos, mas identificou questionamento quanto ao formato que não permitia a reavaliação das respostas ao questionário eletrônico. Nossas avaliações não geraram esse tipo de questionamento, já que os questionários eram respondidos manualmente, permitindo aos alunos reavaliar suas respostas antes da finalização. Por mais que se tenha destacado a pesquisa quantitativa no transcorrer deste ensaio empírico, não se tem como pretensão minimizar a importância da análise qualitativa. Bardin (FARAGO, C. C.; FOFONCA, E. 2012) assinalou que as abordagens qualitativas e quantitativas são complementares, conferindo validade e confiabilidade a pesquisa e suscitando o aparecimento de questionamentos, interrogações e gerando novas propostas no plano metodológico. Conforme Bardin já afirmava em 2009, nem todo o material de análise permite uma amostragem numericamente significativa, mas se o material for demasiadamente importante, devemos reduzir o próprio universo e considerá-lo. Isto nos pareceu ter ocorrido com a afirmativa relacionando o uso das imagens nos casos clínicos com uma maior motivação para o aprendizado (MOZZATO, A. R.; GRZYBOVSKI, D. 2011). Foi utilizado um auditor externo para rever a avaliação qualitativa para confirmar a validade e a confiabilidade da pesquisa, conforme sugerido por Triviños (TRIVIÑOS, A. N. S. 1987). Nosso estudo difere do 
aprendizado colaborativo baseado em casos testado na Universidade de Harvard em 2016 onde alunos de medicina e odontologia foram avaliados. Naquele estudo, após uma leitura prévia, os alunos participaram de atividades baseadas em caso durante a classe, respondendo individualmente a questões e depois discutindo as respostas em grupos de quatro, que depois determinavam consensos em grupos maiores de dezesseis (KRUPAT E; RICHARDS J.B.; SULLIVAN A.M.; FLEENOR T.J. JR; SCHWARTZSTEIN R.M. 2016) Em nossa casuística utilizamos preleção dialogada associada a casos clínicos em momentos distintos e analisamos o resultado, não só desta associação, como da influência do momento em que o caso é inserido na preleção. Verificamos que a utilização do ensino baseado em casos teve uma relação direta com resultados melhores na avaliação final, comparandoos ao da turma anterior, diferentemente do trabalho de Harvard, que não mostrou diferença significativa nas avaliações finais, demonstrando melhora somente dos alunos com resultados piores e sugerindo resultado positivo na motivação e engajamento destes alunos.

A responsabilidade do cuidado do paciente é um poderoso estímulo para o aprendizado e o aprendizado ativo exige e estimula o desenvolvimento de habilidades clínicas, permitindo que as dimensões cognitivas e procedurais sejam apreendidas durante o cuidado do paciente supervisionado pelo professor (SANCOVSCHI, B.; KASTRUP, V. 2013). Os médicos novatos precisam praticar suas habilidades sob a orientação de professores médicos experientes, até que obtenham um alto nível de proficiência. Esse professor, porém, não deve se colocar em um lugar privilegiado, pois seu papel é estimular o desenvolvimento livre e espontâneo do aluno, auxiliando na formação do seu raciocínio clínico (DUPRET, L. M.; et al. 2011). O ensino baseado em casos incentiva os alunos criando uma situação problema, dispondo de informações para estimular a reflexão e a busca de soluções, garantindo a oportunidade de colocar as soluções à prova, a fim de determinar sua utilidade para sua vida profissional, como já afirmava Luckesi (LUCKESI, C. C. 1990). Miller (MILLER, D. R. 2004) demostrou em seu estudo que um estudante motivado melhora seu desempenho no resultado final do aprendizado, o que confirmamos em nosso estudo. A utilização da tecnologia audiovisual foi descrita como um facilitador do aprendizado pelos alunos, o que já fora descrito por John Distler e John Bligh (DISTLER, J. W. 2008) em seus estudos. Estes autores concluíram também que o contato com paciente real é importante para 
aplicação da teoria aprendida, proporcionando uma nova oportunidade para a criação de novas questões.

Apesar dos alunos do quarto ano manterem contato diário com os pacientes ambulatoriais e internados durante todo o rodízio de três meses na pediatria, um aluno sugeriu que seria desejável um tempo ainda maior com os pacientes para utilizar e sedimentar o conhecimento adquirido.

Apesar de existirem estudos publicados sobre a metodologia do estudo de casos no Brasil, são poucas publicações sobre o tema, principalmente na graduação de medicina, de modo que se torna relevante retomar a temática, pela expressividade desse instrumento metodológico para o aprimoramento do processo ensino-aprendizagem entre os graduandos de medicina. 


\section{8 \\ CONCLUSÕES}

Existirá sempre um confronto entre a cultura do aluno e a enorme carga de novos conhecimentos e posturas necessária para sua transformação em um profissional habilitado, entre seu modo de viver e os modelos sociais impostos pela sociedade, desejáveis ou não. Ao lado dele estará o professor, que passou pelos mesmos conflitos, e que poderá intervir, não para se opor aos desejos e necessidades ou à liberdade e autonomia do aluno, mas para ajudá-lo a ultrapassar suas necessidades e criar outras, para propiciar o progressivo ganho de autonomia, para ajudá-lo no seu esforço de distinguir a verdade do erro, compreender as realidades sociais e relacioná-las com sua própria experiência. O grau de envolvimento na aprendizagem depende tanto da prontidão e disposição do aluno, quanto do professor e contexto em sala de aula. O tutor age como um guia e ajuda no progresso dos estudantes durante a discussão para que eles cheguem a uma solução para o problema apresentado (DONNER, R. S.; BICKLEY, H. 1993; GOMES, R. 2009). Os estudantes organizam seus pensamentos, identificam a natureza do problema, os fatores envolvidos e se tornam capazes de tomar uma decisão adequada (MEZZARI, A. 2011).

Um dos grandes desafios no aprimoramento da educação médica e da prática profissional é a avaliação da competência clínica. O desenvolvimento desta habilidade depende de como ocorre a aprendizagem do profissional médico. Uma das metodologias utilizadas tem sido o aprendizado baseado em casos. Essa metodologia tem estimulado a busca, com liberdade, por novos saberes, tendo o professor como facilitador desse processo, compartilhando a responsabilidade na construção do conhecimento. A aplicação do método de estudo de caso é importante durante o período de formação, por contribuir na associação e aproximação, entre teoria e prática, criando a possibilidade de vislumbrar que a teoria e a prática são interdependentes, e que desenvolver os conteúdos abordados em sala de aula no campo da prática é de fundamental relevância para a fixação destes, proporcionando uma postura crítico-reflexiva (RAUPP B. 2008). 
Mudanças no modelo de ensino, qualificando o aluno para que ele seja capaz de realizar as investigações acerca do cuidado a pessoa, deixando de ser um mero receptor de informações, engajado na construção do seu próprio conhecimento, são essenciais (TANCREDI, F. B.; FEUERWERKER, L. C. M. 2001).

Foi interessante notar que, ao longo da apresentação e do desenvolvimento do método, os discentes se mostraram interessados e motivados em participar e de ter conhecimento dos resultados. Foi um aprendizado para ambos e uma troca muito produtiva. O uso de casos clínicos estimulou e ajudou a sedimentar o aprendizado, o que foi confirmado tanto pelas avaliações teóricas realizadas após a preleção dialogada e na prova escrita aplicada após o término do rodízio na especialidade, quanto no questionário opinativo respondido no final do módulo. 


\section{9 \\ REFERENCIAS BIBLIOGRÁFICAS}

1. AAMC Institute for Improving Medical Education. Effective use of education technology in medical education. Colloquium on educational technology: recommendations and guidelines for medical educators. March 2007. Disponível em: https://members.aamc.org/eweb/upload/Effective\%20Use\%20of\%20Educ ational.pdf. Acesso em 12 out. 2016.

2. ALMEIDA, A. P. S.; SOUZA, N. V. D. O. Estudo de caso: uma estratégia para construção de atitude crítico-reflexiva em discente de enfermagem. Rev enferm UERJ, Rio de Janeiro, v. 13, p. 204-9, 2005

3. ALMEIDA. M. J. et al. Implantação das Diretrizes Curriculares Nacionais na graduação em Medicina no Paraná. Revista Brasileira de Educação Médica. Rio de Janeiro, v.31, n 2. P 156-165, 2007.

4. AMOAKO-SAKYI, D.; AMONOO-KUOFI, H. Problem-based learning in resource-poor settings: lessons from a medical school in Ghana. BMC Medical Education, Londres, v. 15, p. 221, 2015

5. AMORETTI, R. A Educação Médica diante das necessidades Sociais em Saúde. Revista Brasileira de Educação Médica, Rio de Janeiro, v.29, n.2, p. 136-146, maio/agosto de 2005.

6. Association of American Medical Colleges. Physicians for the Twenty-First Century. The GPEP Report: Report of the Panel on the General Professional Education of the Physician and College Preparation for Medicine. Washington D. C., 1984, 61p.

7. BLIGH, J. Problem-based learning in medicine: an introduction. Techniques in medical education. Postgrad Med J, Londres, v. 71, p. 323326, 1995

8. BRASIL. Lei Federal número 9.394 de 20 de dezembro de 1996. Estabelece as diretrizes e bases da educação nacional. Diário Oficial da União, Brasília, p. 27833, 23 dez. 1996.

9. BRASIL. Resolução CNE/CES no 4, de 7 de novembro de 2001. Institui Diretrizes Curriculares Nacionais do Curso de Graduação em Medicina. Diário Oficial da União, Brasília, Seção 1, p. 38, 9 nov. 2001.

10. BRASIL. Resolução $n^{\circ} 3$, de 20 de junho de 2014. Institui Diretrizes Curriculares Nacionais do Curso de Graduação em Medicina e dá outras providências. Diário Oficial da União, Brasília, Seção 1B p. 8-11, 23 jun. 2014

11. BRIAN, M.; PAT, D. The use of case studies as a learning method during pre-registration critical care placements. Nurse Educ Pract, Amesterdã v. 4, p. 208-15, 2004

12. BULCÃO, L. G.; EL-KAREH, A. C.; SAYD, J. D. Ciência e ensino médico no Brasil (1930-1950). v. Hist. cienc. saude-Manguinhos, Rio de Janeiro, v. 14, n. 2, p. 469-487, abr.-jun. 2007

13. COOKE, M.; et al. American Medical Education 100 years after Flexner report. N Engl J Med, Boston, v. 355, n. 13, p. 1339-1344, set, 28, 2006

14. DA SILVA, R. S.; et al. Estudo de caso como uma estratégia de ensino na graduação: percepção dos graduandos em enfermagem. Revista CUIDARTE, Santander, v. 5, n. 1, p. 606-612, jun. 2014. 
15. DISTLER, J. W. Using Problem-Based Learning in Teaching Advanced Health Assessment: An Innovative Approach. Topics in Advanced Practice Nursing e-Journal, Nova York v. 8, n. 2, p.1-3, 2008. Disponível em: http://www.medscape.com/viewarticle/575328 Acesso em: 12 out. 2016.

16. DONNER, R. S.; BICKLEY, H. Problem-based learning in American medical education: an overview. Bulletin of the Medical Library Association, Chicago v. 81, n. 3, p. 294-298, Jul. 1993.

17. DUPRET, L. M.; et al. A abordagem de ensino-aprendizagem baseado em casos com o uso de tecnologias de informação e comunicação (TICs) como estratégia frente aos desafios de formação crítica de profissionais de saúde. In: Encontro Nacional de Pesquisa em Educação em Ciência, 8., 2011, Campinas. Atas eletrônicas. Disponível em: <http://www.nutes.ufrj.br/abrapec/viiienpec/resumos/R1256-1.pdf> Acesso em: 12 out. 2016

18. FARAGO, C. C.; FOFONCA, E. A análise de conteúdo na perspectiva de Bardin: do rigor metodológico à descoberta de um caminho de significações. Revista Linguasagem, São Carlos, ed. 18, 2012, disponível em: <http://www.letras.ufscar.br/linguasagem/edicao18/artigos/007.pdf> Acesso em: 12 out. 2016.

19. GOMES, R.; et al. Aprendizagem baseada em problemas na formação médica e currículo tradicional de medicina: uma revisão bibliográfica. Rev. bras. educ. med., Rio de Janeiro, v. 33, n. 3, p. 444-451, 2009

20. HERNANDEZ, C. C.; et al. Avaliação da Aprendizagem em Medicina Baseada em Casos Clínicos: proposta de um ambiente dedicado. Anais dos Workshops do CBIE 2012. Disponível em: < http://www.brie.org/pub/index.php/wcbie/article/view/1948>. Acesso em: 9 out. 2016, 17:14:00

21. KRUPAT E; RICHARDS J.B.; SULLIVAN A.M.; FLEENOR T.J. JR; SCHWARTZSTEIN R.M. Assessing the Effectiveness of Case-Based Collaborative Learning via Randomized Controlled Trial. Acad Med, Philadelphia, V. 91, n. 5, p.723-9. 2016

22. LIMA, V. V. Competência: distintas abordagens e implicações na formação de profissionais de saúde. Interface - Comunic., Saúde, Educ., Botucatu, v.9, n.17, p.369-79, mar/ago 2005.

23. LOPES, A. D.; LICHTENSTEIN, A. William Osler. Rev Med, São Paulo, v. 86, n. 3, p. 185-188, jul/set. 2007

24. LUCKESI, C. C. Tendências pedagógicas na prática escolar. in: Filosofia da educação, São Paulo, Cortez, p. 53-76, 1990.

25. MATOS, J. Transcrição de FRANCO, M. L. P. B. Análise de Conteúdo. 3 ed. Brasília: Liber, p. 69-79, 2008. Disponível em: https://prezi.com/fkbfcuog_4qk/franco-maria-laura-p-b-analise-deconteudo-3-ed-brasili/ Acesso em: 12 out. 2016

26. MEZZARI, A. O uso da aprendizagem baseada em problemas (ABP) como reforço ao ensino presencial utilizando o ambiente de aprendizagem Moodle. Rev Bras de Educação Médica, Rio de Janeiro, v. 35, n. 1, p. 114121,2011

27. MILLER, D. R. Longitudinal assessment of critical thinking in pharmacy students. Am J Pharm Educ., Alexandria, v. 68, n. 1, a. 5, 2004 
28. MOZZATO, A. R.; GRZYBOVSKI, D. Análise de conteúdo como técnica de dados qualitativos no campo da administração: Potencial e Desafios. RAC, Curitiba, v. 15, n. 4, p. 731-747, jul. /ago. 2011

29. OYLER, D. R.; ROMANELLI, F. The Fact of Ignorance: revisiting the Socratic method as a Tool for Teaching Critical Thinking. Am J Pharm Educ, Alexandria, v. 78 n. 7, 2014

30. PAGLIOSA, F. L.; DA ROS, M. A. O relatório Flexner: para o bem e para o mal. Rev. bras. educ. med., Rio de Janeiro, v.32, n.4, p.492-499, 2008. Disponível em: http://www.scielo.br/scielo.php?script=sci_arttext\&pid=S0100$55022008000400012 \& \operatorname{lng}=$ en\&nrm=iso Acesso em 12 out. 2016

31. POMBO O. A interdisciplinaridade. Conceito, problemas e perspectivas. In. POMBO O.; GUIMARÃES, H. M.; LEVY, T. A interdisciplinaridade: reflexão e experiência. Texto, Lisboa. Ed. 2, p. 8-14, 1994.

32. RAMOS, P. Análise do desenvolvimento do artefato pedagógico. In: Ambiente virtual vivências: análise do processo de desenvolvimento na perspectiva da pesquisa baseada em design. Tese (Doutorado em Educação em Ciências e Saúde) - NUTES, UFRJ, Rio de Janeiro, c. 2.2.2, p. 37-43, $2010 . \quad$ Disponível: http://www.nutes.ufrj.br/doutorado/arquivos/t4.PaulaRamos.pdf $>$ Acesso em: 12 out. 2016.

33. RAUPP B. Sistematização de uma metodologia gerencial para unidades de atenção primária do sistema único de saúde no contexto de uma pesquisa sobre a cultura organizacional. Rev. APS, Juiz de Fora, v. 11, n. 4, p. 421434, out./dez. 2008

34. RÉA-NETO, A. Raciocínio clínico - o processo de decisão diagnóstica e terapêutica. Rev Ass Med Brasil, v. 44, n.4, p.301-11, 1998

35. RIBEIRO, C. Metacognição: um apoio ao processo de aprendizagem. Psicol. Reflex. Crit., Porto Alegre, v. 16, n. 1, p. 109-116, $2003 . \quad$ Disponível em: $<$ http://www.scielo.br/scielo.php?script=sci_arttext\&pid=S010279722003000100011\&lng=en\&nrm=iso>. Acesso em 12 out. 2016

36. SANCOVSCHI, B.; KASTRUP, V. Práticas de estudo contemporâneas e a aprendizagem da atenção, Psicologia \& Sociedade, Porto Alegre, v. 25, n.1, p. 193-202, 2013

37. TANCREDI, F. B.; FEUERWERKER, L. C. M. Impulsionando o movimento de mudanças na formação dos profissionais de saúde. Olho Mágico, Londrina, v. 8, n. 2, mai./ago. 2001

38. TAUBER, A. I. The two faces of medical education: Flexner and Osler revisited. J. R. Soc. Med., Londres, v. 85, p. 598-602, out. 1992

39. TRIVIÑOS, A. N. S. Pesquisa qualitativa in TRIVIÑOS, A. N. S. Introdução à Pesquisa em Ciências Sociais: A Pesquisa Qualitativa em Educação. São Paulo: Atlas, 1987. p. 116-173 


\section{0 \\ ANEXO I}

\section{1}

\section{CASOS CLÍNICOS DE FEBRE REUMÁTICA}

CASO 1 - Paciente de 8 anos, masculino, com história de artrite de joelho direito e tornozelo esquerdo com duração de 3 dias em cada um. Mãe nega quadro infeccioso recente ou febre. Ao exame apresenta-se hipocorado, taquicardico, com sopro sistólico em foco mitral, irradiando para axila.

CASO 2 - Criança de seis anos, veio ao ambulatório de pediatria por apresentar há 15 dias dificuldades na escola. Já estava lendo muito bem, escrevendo corretamente, quando nesse período a professora notou que a mesma não consegue mais escrever na linha e que na hora da leitura não consegue ler, porque enrola a língua e não sai nada. Anda chorando muito e não consegue ficar parada. A responsável nega qualquer outro sintoma, refere somente amigdalites frequentes, tratadas com sulfa por 10 dias.

CASO 3 - Uma criança de 5 anos procurou o pediatra com história de febre há 3 dias e artralgia do joelho direito e do tornozelo esquerdo, que prejudicaram a deambulação por 24 h e desapareceram no 20 dia, sem uso de qualquer medicação. Ao exame físico observa-se hiperemia de orofaringe. $\mathrm{O}$ hemograma mostrou $\mathrm{Ht}=$ $34 \%$, leucometria de 7.200 com contagem diferencial 0/3/0/2/32/59/4, VHS de 10 mm/h. PCR (-), ASO = 400 UI, mucoproteína normal.

CASO 4 - Criança de 6 anos é trazida ao ambulatório de Pediatria apresentando febre não aferida há 4 dias, associada a aumento de volume e calor em joelho direito. Apesar de causar grande incapacidade funcional, a dor melhorou em 24 h com uso de anti-inflamatório não hormonal. A mãe nega qualquer outra sintomatologia, exceto por febre alta há 15 dias com odinofagia, tratada com amoxicilina por 5 dias. Ao exame a criança encontra-se ativa, reativa, hidratada, $\mathrm{FR}=16 \mathrm{ipm}, \mathrm{FC}=130 \mathrm{bpm}, \mathrm{PA}=80 \times 40 \mathrm{mmhg}$, com perfusão satisfatória. Precórdio hiperdinâmico. Restante do exame sem anormalidades 


\section{2}

\section{CASOS CLÍNICOS DE DORES NOS MEMBROS}

CASO 1 - Há aproximadamente 5 meses, criança de 5 anos, filha de pais em processo de divórcio litigioso, refere dor profunda bilateral de localização vaga em porção anterior de ambas as pernas, coxas, panturrilhas e oco poplíteo. A dor interrompe brincadeiras e é sempre pior à noite, muitas vezes acordando o paciente. Melhora com massagem, repouso e anti-inflamatórios. Exame físico normal.

CASO 2 - Há 4 meses, criança de 8 anos apresenta queixa de claudicação periódica. Evoluiu com dor na articulação do joelho direito há 1 mês. A dor se intensifica quando se exercita muito, é pior à noite e eventualmente melhora com anti-inflamatório. Ao exame físico verifica-se atrofia do membro inferior e da região glútea direitos, com limitação dos movimentos de abdução do quadril do mesmo lado.

CASO 3 - Criança de 9 anos com quadro de febre não aferida, aumento de volume, calor e dor incapacitante no joelho direito há $48 \mathrm{~h}$. Foi atendida em emergência hospitalar, onde foi imobilizada e orientada a utilizar AINH durante 7 dias. Apresentou melhora da manifestação articular, porém evoluiu com sopro sistólico em foco mitral e taquicardia. Há relato de "dor de garganta" há 10 dias, tratada com gargarejo e AINH.

CASO 4 - Criança de 10 anos com quadro de aumento de volume e dor em ambos os tornozelos e joelhos há dois meses, acompanhado de febre intermitente. A dor é pior pela manhã e melhora ao longo do dia. Associado a este quadro apresenta derrame pleural e rash eritematoso evanescente em tronco. Melhora com anti-inflamatórios. Ao exame evidencia-se artrite de tornozelos e joelhos com atrofia da musculatura da ambas as coxas e panturrilhas. Paciente febril $\left(38,5^{\circ} \mathrm{C}\right)$, com diminuição de MV bilateralmente.

CASO 5 - Criança de 6 anos com baixa estatura, dor na coluna e quadris, encurtamento dos membros, dor e limitação dos movimentos articulares. 


\section{3}

\section{CASOS CLÍNICOS DE SEPSE}

CASO 1 - Recém-nascido é trazido a emergência por apresentar febre alta associada a perda ponderal e dificuldade de sucção. Ao exame apresenta-se pálido, hipocorado $(++/ 6+)$, taquicardico, abdômen distendido, fazendo pausas respiratórias durante o exame físico. Pulsos filiformes. Hemograma com leucocitose e desvio para esquerda. EAS com piúria e nitrito positivo.

CASO 2 - Lactente de oito meses apresentando febre $\left(38,5^{\circ} \mathrm{C}\right)$, vômitos e diarreia pastosa, sanguinolenta (cinco episódios por dia há 72 horas). Evoluiu com sonolência, taquicardia mesmo quando afebril, taquipneia e hipotensão

CASO 3 - Adolescente colocou um "piercing" na orelha. Evoluiu com hiperemia, edema e calor no local, de onde iniciou drenagem de secreção purulenta. Não procurou atendimento, evoluindo com agitação, hipotensão, taquipneia, tosse e cianose periférica 